\title{
Biochemical Studies of Eucalyptus as an Antitumor in Mice
}

\author{
Nabila Zein *1, Enaiat K. Mohamed ${ }^{2}$, Fatma EL Zahraa El Sayed 1 \\ ${ }^{1}$ Biochemistry Division, Chemistry Department Faculty of Science, Zagazig University, Egypt \\ ${ }^{2}$ Chemistry Department, Faculty of Science, Zagazig University, Egypt
}

\begin{tabular}{l}
\hline A R T I C L E I N F O \\
\hline Article history: \\
Received \\
Accepted \\
Available online
\end{tabular}

Keywords: IL-10; Polymorphism; $\mathrm{HCV}$.

\begin{abstract}
A B S TR AC T
Eucalyptus camaldulensis Dehnh (Myrtaceae) is used in traditional folk medicine for the treatment of various health complications are well known. The current study aimed to investigate the antitumor efficacy of Eucalyptus camaldulensis stem bark methanol extract (ECME) against Ehrlich ascites carcinoma (EAC) bearing Swiss albino mice. The extract was proved by chemical analysis and LD50 was determined. Then, mice were injected intraperitoneally with ECME (100mg / $\mathrm{kg} \mathrm{b.wt)}$ before and after EAC inoculation, to achieve preventive and therapeutic effects daily, for 9 days. Estimating biochemical parameters of experimental mice as malondialdehyde (MDA), total antioxidant capacity (TAC) were estimated, Cytological studies on EAC cells and histopathological examination of liver and kidney tissue were carried out. Treatment with ECME decrease the level of (MDA) associated with increase in (TAC) in preventive and therapeutic groups compared to positive control group. Treatment with ECME reduced most of the pathological alterations induced by EAC cells in mice. This confirmed that ECME caused EAC cell death. The high LD50 value $(1120 \mathrm{mg} / \mathrm{kg})$ of ECME indicated its low host toxic effects. The present work indicates that ECME possess significant antitumor and antioxidant activity in vivo. Thus, E. camaldulensis may be considered as a promising resource in cancer chemotherapy.
\end{abstract}

(C) 2016 Publisher All rights reserved

\section{Introduction:}

Cancer continues to represent the largest cause of mortality in the world and claims over 6 million lives every year [1]. An extremely promising strategy for cancer prevention today is chemoprevention, which is defined as the use of synthetic or natural agents (alone or combination) to block the development of cancer in humans. Many chemotherapeutic drugs used in cancer treatment are derived from plants. The plant used in the present study is Eucalyptus camaldulensis Dehnh (Myrtaceae) which growing on the margins of the ponds and banks of the Nile-river and is planted all over the Egypt. The plant showed strong antibacterial activity[2], antinociceptive effects[3], antioxidant activity [4], cytotoxic 
activity against human ECV-304 cells, reduced the viability of many cell lines [5].Chemical composition of Eucalyptus has antioxidant, anti- Inflammatory and antiProliferative activities [6]. Extracts from this plant also showed protective effects, antiproliferative effect and anticancer activity against EAC cells and triggers apoptosis and cell cycle changes in Ehrlich EAC as reported before $[7,8]$. Therefore, the present study was designed to evaluate the in vivo cytotoxic and antitumor activity of ECME against Ehrlich ascites carcinoma (EAC) in mice.

\section{Material and methods}

\section{1-Plant material and preparation of extracts}

Collection: The plant materials were collected from the Garden of Agricultural Museum at Cairo, Egypt, and were kindly identified and proved by Herbarium of Botany department, faculty of Science, Zagazig University. The collected stem bark was shade-dried and reduced to coarse powder. The dried powder was extracted with methanol at room temperature for 14 days. The extract was then distilled, evaporated, dried and stored in a vacuum container for further use [9]. Phytochemical screening: The phytochemical components of the plant were analyzed for saponins, saponin glycosides, steroid, glycosides, anthraquinones, tannins, flavonoids, alkaloid, volatile oils, phenols and balsam (gum) using standard methods described by pandey etal[10].

Determination of median lethal dose (LD50): The extract was injected intraperitoneally to eight groups of mice at different doses [900, 1000, 1050, 1100, $1120,1150,1200$ and $1250 \mathrm{mg} / \mathrm{kg}$ (I.P.)] to determine acute toxicity according to Khanam et al. [11].

2-Experimental animals: A total of 40 adult female Swiss albino mice at 8 weeks of age (average
18-25 $\mathrm{g}$ in weight) were obtained from the laboratory animal farm of Veterinary Medicine at Zagazig University, Egypt.

3-Ehrlich ascites carcinoma cells: The parent line of Ehrlich ascites carcinoma cells was kindly supplied by the National Cancer Institute, Cairo University. The tumor line was maintained by serial intraperitoneal transplantation of Ehrlich ascites carcinoma $2.5 \times 10^{6}$ tumor cells/ 0.2 $\mathrm{ml}$ in female Swiss albino mice [12].

1-Experimental design: 40 female Swiss albino mice were weighted and divided into 4 different groups, 10 mice per group as follow: Group 1: Negative control group was injected i.p. with $(0.3 \mathrm{ml} / \mathrm{mouse})$ saline only daily. Group 2: Positive control group was injected i.p. with EAC cells by the concentration of $\left(2.5 \times 10^{6}\right.$ cells / 0.3 $\mathrm{ml} /$ mouse), once at the beginning of the experiment. Group 3: Preventive group was injected i.p with ECME at the dose of 100 $\mathrm{mg} / \mathrm{kg}$ at the beginning of the experiment, at the second day mice were injected i.p. with EAC cells by the concentration of $2.5 \times$ $10^{6} / 0.3 \mathrm{ml} /$ mouse once, then the day after mice were injected i.p with ECME at the dose of $100 \mathrm{mg} / \mathrm{kg}$. Group 4: Therapeutic group was injected i.p. with EAC cells by the concentration of $2.5 \times 10^{6} / 0.3 \mathrm{ml} /$ mouse once at the beginning of the experiment, at the second day mice were injected i.p with ECME at the dose of $100 \mathrm{mg} / \mathrm{kg}$. Mice in group 3 and 4 injected i.p with ECME at the dose of $100 \mathrm{mg} / \mathrm{kg}$ daily for 9 days, till the end of the experiment. After 9 days of treatment, animals from each group were sacrificed.

Sampling of blood and EAC cells: At the end of the experiment, the blood samples were collected from the retro-orbital venous plexus under light ether anesthesia. Serum was prepared by centrifuging blood at 4000 r.p.m for 10 minutes. Serum samples were aliquoted and stored at $-20^{\circ} \mathrm{C}$ until biochemical analysis.

Biochemical Parameters: 1) Determination of serum, liver malondialdehyde level was 
assayed by using Biodiagnostic kit method (Biodiagnostic Company, Giza/Egypt) according to Satoh et al. [13].

2) Determination of Total antioxidant capacity (TAC) was assayed by using Biodiagnostic kit method (Biodiagnostic Company, Giza/Egypt) according to Koracevic et al. [14]. Histopathological Study: Histopathological examination of liver and kidney tissue, Specimens were fixed in $10 \%$ neutral buffered formalin. Paraffin sections of $5 \mu$ thickness were prepared from all specimens and were stained by haematoxylin and eosin (H\&E) and examined microscopically [15].

Cytological Study: Cytological study on EAC cells was carried out according to the method described by Rahman [16].

Statistical Analysis: Statistical analysis of data was performed by using SPSS 14.0 version using one way analysis of variance (ANOVA) according to the method described by [17] numerical data were expressed as mean $+\mathrm{SD}, \mathrm{P}$ values $<0.05$ were considered to be statistically significant.

\section{Results:}

1-The phytochemical analysis of the current study observed the presence of a large number of bio active compounds in the ECME including: Triterpenoids, saponins, tannins, flavonoids, phenols and steroids.

2- The high LD50 value $(1120 \mathrm{mg} / \mathrm{kg})$ of ECME indicated its low host toxic effects.

3- There is significant difference between Therapeutic, Preventive group compared to positive control group. The significant decrease in the level of Malondialdehyde (MDA) associated with significant increase in Total Antioxidants Capacity (TAC).

4-cytological examination of EAC cells illustrated in Fig (1).Positive control group: Photomicrograph of peritoneal aspirate showing large number of variable sized malignant cells(large, medium and small) with pleomorphic hyper chromatic nuclei and eosinophilic cytoplasm (H\&E $\mathrm{x} 400)$. Therapeutic group:
Photomicrograph of peritoneal

5-aspirate showing moderate number of malignant cells with pleomorphic hyperchromatin nuclei and scanty eosinophlic cytoplasm (H\&E x400). Preventive group: Photomicrograph of peritoneal aspirate showing scattered reactive mesothelial cells surrounded by inflammatory cells (H\&E x400).

6-Histopathological investigation of mice liver tissue presented in Fig (2). Negative control group: Photomicrograph of normal liver tissue formed of central veins surrounded by rows of polyhedral hepatocytes with central nuclei and eosinophilic cytoplasm (H\&E x200). Positive control group: Photomicrograph of liver tissue showing dilated congested central vein surrounded by lobules of hepatocytes with central nuclei and eosinophilic cytoplasm, The lobules of hepatocytes are separated by dense fibrous bands and heavy aggregation of chronic inflammatory cells (H\&E x200).Therapeutic group: Photomicrograph of liver tissue showing markedly dilated congested central vein surrounded by rows of hepatocytes and aggregation of inflammatory cells (H\&E x200). Preventive group: Photomicrograph of liver tissue showing central veins surrounding by rows of hepatocytes containing scattered inflammatory cells (H\&E x200).

7-Histopathological examination of mice kidney tissue presented in Fig (3), Negative control group: Photomicrograph of normal renal tissue formed of numerous uniform round glomeruli and renal tubules lined by cubical epthelium and with narrow lumina (H\&E x200). Positive control group: Photomicrograph of renal tissue showing dilated congested renal vein surrounded by renal glomeruli and renal tubules (H\&E x200).Therapeutic group:Photomicrograph of renal tissue showing congested renal vein surrounded by renal glomeruli and renal tubules with 
few aggregates of inflammatory cells $(\mathrm{H} \& \mathrm{E}$ x200).Preventive group: Photomicrograph of normal renal tissue showing round uniform renal glomeruli surrounded by normal renal tubules with patent lumina (H\&E x200).

\section{Discussion:}

Plants contain almost unlimited capacity to generate compounds that fascinates researchers in the quest for new and novel chemotherapeutics, the persistency search for new anticancer compounds in plants medicines is a realistic and promising strategy for its prevention, Numerous compounds found in plants with anticancer properties are such as polyphenolic compounds, tannins, flavonoids, phenylpropanoids and terpenoid [18]. The study has chosen to test anticancer activity of ECME on EAC tumors in mice as such tumors are considered to be undifferentiated carcinoma, hyperdiploid and most sensitive to chemotherapy, Further characteristics of EAC tumors are high transplantable capability, no regression, rapid proliferation, shorter lifespan, $100 \%$ malignancy and resemblance to human tumors [19]. Most anti-cancer drugs are designed to eliminate rapidly proliferating cancerous cells and therefore they show cytotoxicity and induce apoptosis in cancer cells. Several studies have evaluated the relations between anticancer activities of plant extracts and their phenolic content [20], Phenolic compounds are reported to be exerting a direct anticancer action, evident at low concentrations even, Furthermore, the direct interaction with the aryl hydrocarbon receptor, the nitric oxide synthase inhibition and their pro-apoptotic effect provides some insights into their biological modes of action [21].

The phytochemical analysis of the current study observed the presence of a large number of bio active compounds in the ECME including: Terpenoids, saponins, tannins, flavonoids, phenols and steroids. The results agree with those previously recorded $[22,9]$.
The investigation provides evidence for cytotoxicity in Ehrlich's ascites carcinoma due to existing phytochemicals in the extract as polyphenols which have been shown to possess antimutagenic and antimalignant effects, Flavonoids have a chemopreventive role in cancer through their effects on signal transduction in cell proliferation and angiogenesis also expressing superior activity against cancer cells, The cytotoxic and antitumor properties of our extract due to presence of these compounds [18] who agreed with our results. Oršoli et al. [23] revealed that flavonoids, terpenoids and steroids have received considerable attention in recent years due to their diverse pharmacological properties including antioxidant and antitumor activity, the flavonoid components are of the most promising antitumor natural products in general, due to their immunomodulatory activity. Hegazi et al. [22] reported that the presence of flavonoids in the ethanolic extract of propolis was capable of increasing the survival of mice-bearing Ehrlich carcinoma and suggested that the immunostimulatory activity of propolis may be associated with macrophage activation and enhancement of their phagocytic activity.

Free radicals are the molecules that have unpaired electrons in the outermost shell and therefore are unstable and highly reactive. Accumulation of such oxidizing agents, mainly reactive oxygen species (ROS), in the human body induces oxidative damage for DNA and other cellular components leading to cancer initiation and propagation, In contrast, antioxidants neutralize the free radicals by donating one of their own electrons to prevent or delay oxidation of the biomolecules. Thus, antioxidant supplements have been recommended to protect a human body from cancers and other diseases mediated by oxidative stress [24].The improper balance between reactive oxygen metabolites (ROMs) and antioxidant defenses results in "oxidative stress," which deregulates the cellular functions leading to various pathological conditions including cancer, ROMs overproduction induced by 
different exogenous and endogenous mechanism may exhaust

the antioxidant system of cells and contribute to a number of destructive processes and diseases, including cancer [25]. Epidemiological studies have suggested that high endogenous level of oxidative adducts and deficiencies in antioxidant levels are likely to be an important risk factors for cancer [26].Several previous studies have clarified the influence of ROS over production on intracellular $\mathrm{Ca} 2+$ levels, increases in the concentrations of intracellular ROS were a sign of the onset of apoptotic processes; It has been shown that oxidative stress increases intracellular $\mathrm{Ca} 2+$ concentrations, leading to activation of endonucleases which degrade DNA and, ultimately, contribute to cell damage, in nuclei, high $\mathrm{Ca} 2+$ levels modulate transcription factors and nucleases that regulate cell apoptosis [27]

Lipid peroxidation, an autocatalytic free radical chain propagating reaction, is known to be associated with pathological conditions of a cell [25] Malondialdehyde was the end product of LPO was reported to be higher in cancer tissues than in nondiseased organ, It was also reported that the presence of tumors in the human body or in experimental animals was known to affect many functions of the vital organs, especially in the liver, even when the site of the tumor does not interfere directly with organ function[28].Antioxidants with free radical scavenging activities may have great relevance in the prevention and therapeutics of diseases in which oxidants or free radicals are implicated such as cancer [29].

From the results showed in (Table 1) it was cleared that EAC induced oxidative stress caused enhanced lipid peroxidation. Preventive and therapeutic groups showed significant degree of protection against oxidative damage caused by EAC by decreasing lipid peroxidation in comparison with positive control mice, as it was observed that ECME has lowered the MDA level by
$47.79 \%$ in liver and $59.50 \%$ in serum of preventive group in comparison with positive group and have lowered the MDA level by $44.17 \%$ in liver and $57.43 \%$ in serum of therapeutic group in comparison with positive group, the significant decrease in the level of Malondialdehyde (MDA) associated with significant increase in Total Antioxidants Capacity (TAC) by $99.31 \%$ and $83.56 \%$ in preventive and therapeutic group respectively which treated with ECME compared to positive control group. This support that the ECME possesses significant antitumor and antioxidant potential against EAC bearing mice. The results are in agreement with that previously described[30].

Generally there is a relationship between antioxidative activity and oxidative potentials, the lower the oxidative potential of extracts the higher would be the antioxidant capacity and the lower the oxidative potential, the higher is the ability to donate electron easily to the system generated free radicals [27].Typically it reacts with oxidants such as reactive oxygen species such as hydroxyl radical formed from hydroxyl peroxide and reduce it and thereby neutralize reactive oxygen species, such radicals are damaging to animals and plants at the molecular level due to their possible interaction with nucleic acids, proteins, and lipids which can further initiate or propagate the development of many diseases, such as cancer [31]. So we assume that the same mechanism probably works for ECME as the presence of Phenolic compounds as saponin, triterpene and flavonoids. Saponins are potential anticancer agents, with different mechanisms of action, their cytotoxic effects may be due to either apoptosis inducement or non-apoptotic cell death stimulation, saponin was able to stabilize reactive oxygen species by reacting with them and oxidizes subsequently to more stable and less reactive radicals. In this respect saponins in ECME play an important role as antioxidant for prevention of oxidative damage. Anti-tumor activity of these antioxidants is either 
through induction of apoptosis or by inhibition of neovascularization [32].one of the well-known mechanisms of saponins as cytotoxic agents is Caspase 3 activation. Cytotoxic activity of the ECME is mainly due to its inhibition of cell cycle signaling and induction

of apoptosis [6]. Recent research has focused on the ability of flavonoids-type antioxidant compound to increase the concentration of chemotherapeutics in tumor cells. Thus, the presence of flavonoids and the cytotoxic nature of the extract could produce the anticancer effect of ECME against EAC cells [9]. Islam et al. [33] revealed increase in the total antioxidant capacity of seeds of Syzygium Fruticosum extracts. The antioxidant capacity attributed to their chemical composition and phenolic content. Jayaprakasha et al. [34] indicated that the total antioxidant activity of citrus was due to the presence of phenolics, flavonoids and ascorbic acid.

As for the cytological examination of EAC cells illustrated in Fig (1), positive control group revealed a large number of variable sized malignant cells (large, medium and small) with pleomorphic hyper chromatic nuclei and eosinophilic cytoplasm. Therapeutic and preventive groups A, B respectively revealed a few number of malignant cell surrounded by scattered inflammatory cells compared to positive control group. Reduction in number of malignant cells in Preventive and therapeutic group supports the suitability of the ECME as an anticancer agent. The results agree with findings of Badr et al. [35] who stated that the cytological examination of EAC cells (positive control group) showed a significant increase in number of mitotic cells while the cytological examination of EAC cells in both preventive and therapeutic groups respectively revealed a significant decrease in number of mitotic cells compared to positive control group. Moreover, there is no significant difference between preventive and therapeutic groups in the appearance and morphology of EAC cells. Moreover, there is no significant difference between preventive and therapeutic groups in the appearance and morphology of EAC cells.

As for histopathological investigation of mice liver tissue presented in Fig (2), negative control mice liver showing normal blood vessel and normal nucleus and central veins surrounded by rows of polyhedral hepatocytes in the center. Positive control mice liver showed dilated congested central vein surrounded by lobules of hepatocytes with central nuclei and eosinophilic cytoplasm and the lobules of hepatocytes are separated by dense fibrous bands and heavy aggregation of chronic inflammatory cells. Interestingly treatment with ECME reduced most of the pathological alterations induced by EAC cells in mice. The therapeutic mice group liver showed enhancement in the histology of the liver. The preventive mice group, as a whole, the liver tissue showed a normal appearance to a large extent as reflected by normal array of the hepatic cords radiating from the central vein, there is no appearance of cellular inflammatory infiltration, the cytoplasm is intact with normal eosinophelia and the nuclei is similar to negative control ones. From the histopathological examination, there was diminishing in pathological structure to a great degree, towards normal intact histological structure and this is in agreement with [36] who showed that negative control mice liver showing normal blood vessel and normal nucleus and hepatocytes are radiating outward from a central vein in the center. Positive mice liver showed cellular inflammatory infiltration, congestion in blood vessels, hyperchromatinea, nuclear hypertrophy debris in the central vein haemorrhage and wide sinusoids, treatment with balanitoside extract reduced most of the pathological alterations induced by EAC cells in mice.

Also it is showed that animals treated with extract of the Alternanthera brasiliana had a significant improvement in histological feature of liver because of containing antioxidant principles that were cytotoxic 
towards tumor cells [37].And we suggest that ECME enhance the liver condition according to the same mechanism. The present study suggested that ECME exhibits potential antitumor and antioxidant activities in vivo and it possess the apoptosis mechanism, which is preferable because eliminating tumor cells by apoptosis is helpful to lower the side effects in patients by avoiding necrosis [38].

As for histopathological examination of mice kidney tissue presented in Fig (3), negative control mice kidney showing normal renal tissue formed of numerous uniform round glomeruli and renal tubules lined by cubical epthelium and with narrow lumina. Positive control mice kidney showed dilated congested renal vein surrounded by infiltrated renal glomeruli and renal tubules and aggregation of inflammatory cell. Interestingly, treatment with ECME reduced most of the pathological alterations induced by EAC cells in mice. The therapeutic mice group kidney showed enhancement in the histology of the kidney renal tissue showing congested renal vein surrounded by renal glomeruli and renal tubules with few aggregates of inflammatory cells. In preventive mice group, as a whole, the kidney tissue showed normal renal tissue showing round uniform renal glomeruli surrounded by normal renal tubules with patent lumina similar to negative control ones. This is in agreement with Islam[39] and Patra[40] who stated that negative control group showed normal renal tissue formed of numerous uniform round glomeruli and renal tubules lined by cubical epthelium and with narrow lumina. Positive control group renal tissue showing dilated congested renal vein surrounded by infiltrated renal glomeruli and renal tubules and aggregation of inflammatory cells. Therapeutic group renal tissue showing congested renal vein surrounded by renal glomeruli and renal tubules with few aggregates of inflammatory cells. Preventive group normal renal tissue showing round uniform renal glomeruli surrounded by normal renal tubules with patent lumina ,atrophic glomeruli and normal glomeruli surrounded by renal tubules showing hydropic degeneration with obliterated lumina and swollen eosinophilic renal tubular epithelial cells.

\section{Conclusion}

In light of the above observations, it can be concluded that the ECME shows potential anticancer activity. Therefore, it might be considered as a promising resource in cancer chemotherapy with abetter host safety profile. However, before assuming so, it is necessary to carry out extensive research on this plant at a more advanced level, using other cell lines and higher animal models.

\section{References}

[1] Jemal A., DVM, Bray F., Center M.M., Ferlay J., Ward E., et al. Global Cancer Statistics. CA CANCER J CLIN.2011; 61:69-90.

[2] Khan MN, Ngassapa O, Matee MIN. Antimicrobial activity of Tanzanian chewing sticks against oral pthogenic microbes. Pharm Biol.2000; 38:235-40.

[3] Atta AH, Alkofahi A. Anti-nociceptive and anti-inflammatory effects of some Jordanian medicinal plant extracts. J Ethnopharmacol.1998; 60:117-24.

[4] El-Ghorab AH, El-Massry KF, Marx F, Fadel HM. Antioxidant activity of Egyptian Eucalyptus camaldulensis var. brevirostris leaf extracts. Nahrung.2003; 47:41-5.

[5] Abdel-Nasser S, Nahla A, Eman AS.Phenolic constituents of Eucalyptus camaldulensis Dehnh, with potential antioxidant and cytotoxic activities. Rec Nat Prod.2011; 5:271-80.

[6] Bayala B, Bassole IHN, Gnoula C, Nebie $\mathrm{R}$, Yonli A, et al. Chemical Composition, Antioxidant, Anti-Inflammatory and AntiProliferative Activities of Essential Oils of Plants from Burkina Faso. PLoS ONE.2014; 9(3): e92122.

[7] Islam F., Khanam J.A., Khatun M., Zuberi N., Khatun L., Kabir S.R., et al. A pMenth-1-ene- 4,7-diol (EC-1) from 
Eucalyptus camaldulensis Dhnh. Triggers Apoptosis and Cell Cycle Changes in Ehrlich Ascites Carcinoma Cells. Phytother. Res.2015;

[8] Bhagat M., Sharma V. and Saxena A.K. Anti-proliferative effect of leaf extracts of Eucalyptus citriodora against human cancer cells in vitro and in vivo. Indian Journal of Biochemistry \& Biophysics.2012; Vol. 49, pp. 451-457.

[9] Islam F., Khatun H., Khatun M., Ali S.M.M., and Khanam J.A. Growth inhibition and apoptosis of Ehrlich ascites carcinoma cells by the methanol extract of Eucalyptus camaldulensis. Pharm Biol.2013.

[10] Pandey S., Pandey R., Singh R. Phytochemical Screening of Selected Medicinal Plant Cinnamon Zeylanicum bark extract, Area of research; Uttarakhand, India. International Journal of Scientific and Research Publications.2014; Volume 4

[11] Khanam JA, Islam MF, Jesmin M, Ali MM. Antineoplastic activity of acetone semicarbazone(ASC) against ehrlich ascites carcinoma (EAC) bearing mice. J Natn Sci Foundation Sri Lanka.2010; 38(4): 225-231.

[12] Salem F.S, Badr M.O., Neamat-Allah A.N. Biochemical and pathological studies on the effects of levamisole and chlorambucil on Ehrlich ascites carcinoma bearing mice. Vet Italiana.2011; 47(1): 8995.

[13] Satoh K. Serum lipid peroxide in cerebrovascular disorders determined by a new colorimetric method .Clinic Chimica Acta.1978; 90:37-43.

[14] Koracevic D, Koracevic G, Djordjevic V, Andrejevic S, Cosic V. Method for the measurement of antioxidant activity in human fluids.J Clin Pathol.2001; 54(5):356361 .

[15] Ali MM, Jesmin M. Hepatotoxicity of Schiff bases derived from benzoin salicylaldehyde, aminophenol and 2,4 dinitrophenyl hydrazine. J Natn Sci Foundation Sri Lanka.2010; 38(2): 145149.
[16] Rahman SNSA, Norhanom AW, Nurestri AMS.In vitro morphological assessment of apoptosis induced by antiproliferative constituents from the rhizomes of Curcuma zedoaria. Evid Based Complement Alternat Med.2013; 2013:1-14.

[17] Levesque R SPSS. Programming and Data Management: A Guide for SPSS and SAS Users, Fourth Edition SPSS Inc.Chicago.2007

[18] Prema Kumari and Louis Jesudas.Int.J.Bioassays.2014; 3 (01), 16991707.

[19]Mehmet O, Isik DK, Ibrahim HK, Muhammed EG.Ehrlich ascites carcinoma. Afr J Biotechnol.2011; 10:2375-8.

[20] Shoieb A, Elgayyar, M, Dudrick P, Bell J, Tithof P.In vitro inhibition of growth and induction of apoptosis in cancer cell lines by thymoquinone.International Journal of Oncology.2003; 22(1), 107- 113.

[21] Kampa M, Alexaki VI, Notas G, Nifli AP, Nistikaki A, Hatzoglou A, et al."Antiproliferative and apoptotic effects of selective phenolic acids on T47D human breast cancer cells: potential mechanisms of action." Breast Cancer Res.2004; 6, R63R74.

[22] Hegazi A.G., Ragaa H.M. Altahtawy, Amr M. Abdou and Fyrouz Abd Allah. Egyptian Propolis 10: It's Effect on Hematological Changes and Bacterial Load in Mice-Bearing Ehrlich Ascites Carcinoma and Concurrently Infected with Staphylococcus aureus. Academic Journal of Cancer Research.2014; 7 (3): 215-223.

[23] Oršoli N. A review of propolis antitumour action in vivo and in vitro.Journal of Api. Product and Api. Medical Science.2010; 2(1): 1-20.

[24] Poljšak B. and Fink R.The Protective Role of Antioxidants in the Defence against ROS/RNS- Mediated Environmental Pollution. Hindawi Publishing Corporation Oxidative Medicine and Cellular Longevity.2014; Article ID 671539, 22 pages 
[25] Mamatha G.C., Prabhakar T., Naitik P., Madhuri V., Neelima K. and Erumalla V.N.R. Antitumor Activity and Antioxidant Status Of Euphorbia Thymifolia Linn Against Ehrlich ascites carcinoma in Swiss albino mice. World Journal of Pharmaceutical Research.2014; Volume 3 [26] Pandya NB., Tigari P., Dupadahalli K., Kamurthy H., and Nadendla R.R. Antitumor and antioxidant status of Terminalia catappa against Ehrlich ascites carcinoma in Swiss albino mice.Indian J Pharmacol.2013; 45(5): 464-469.

[27] Sharma P., Jha A.B., Dubey R.S. and Pessarakli M. Reactive Oxygen Species, Oxidative Damage, and Antioxidative DefenseMechanism in Plants under Stressful Conditions. Hindawi Publishing Corporation Journal of Botany.2012; Volume Article ID 217037, 26 pages

[28] Elsaid F.G. The Effect of Seeds and Fruit Pulp of Adansonia digitata L.(Baobab) on Ehrlich Ascites Carcinoma.Food and Nutrition Sciences.2013; 4, 38-46.

[29] Mayo Clinic. Antioxidants: Preventing Diseases, Naturally. Science Daily.2007

[30] Isler D., Ozaslan M., Karagoz I.D., Kilic I.H., Karakok M., Taysi S., et al. Antitumoral effect of a selective Rho-kinase inhibitor Y27632 against Ehrlich ascites carcinoma in mice.Pharmacological Reports.2014; 66, 114-120.

[31] Raushanara A, Raquibul H S M, Mokarram H M, Mariam J, Sultana S C, Mazumder M E H, et al. Antidiarrhoeal and Antioxidant Properties of Curcuma alismatifolia Leaves. Australian J. of Basic and Applied Sciences.2010; 4(3): 450-456.

[32] Alam B., Majumder R., Akter S. and Lee S. Piper betle extracts exhibit antitumor activity by augmenting antioxidant potential. Oncology Letters.2015; 9: 863-868.

[33] Islam S., Nasrin S., Khan M.A., Hossain ASM S., Islam F., Khandokhar P., et al. Evaluation of antioxidant and anticancer properties of the seed extracts of Syzygium fruticosum Roxb growing in Rajshahi, Bangladesh. BMC Complementary and Alternative Medicine.2013; 13:142.

[34] Jayaprakasha GK, Girennavar B, Patil BS.Radical scavenging activities of Rio Red grapefruits and Sour orangefruit extracts in different in vitro model systems. Biores Tech.2008; 99:4484-4494.

[35] Badr M.O.T., Edrees N.M.M, Abdallah A.A.M, Hashem M.A., Nasr El-Deen A.M.N., Neamat-Allah A.N F., et al.Synergistic anti-tumour effect of propolis against Ehrlich carcinoma.Journal of American Science.2012; 8(1).

[36] Al-Ghannam S.M., Ahmed H.H., Zein N., Zahran F. Antitumor Activity of Balanitoside Extracted from Balanites aegyptiaca Fruit. Journal of Applied Pharmaceutical Science.2013; Vol. 3 (07), pp. 179-191.

[37] Samudrala P.K., Augustine B.B., Kasala E.R., Bodduluru L.N., Barua C., and Lahkar M. Evaluation of antitumor activity and antioxidant status of Alternanthera brasiliana against Ehrlich ascites carcinoma in Swiss albino mice. Pharmacognosy Res.2015; 7(1): 66-73.

[38] Shuli M, Wenyuan G,Yanjun Z, Luqi H, Changxiao L. Chemical study and medical application of saponins as anti-cancer agents. Fitoterapia.2010; 81: 703-714.

[39] Islam F., Ghosh S., Khanam J.A. Antiproliferative and hepatoprotective activity of metabolites from Corynebacterium xerosis against Ehrlich Ascites Carcinoma cells. Asian Pacific Journal of Tropical Biomedicine.2014

[40] Patra and Muthuraman. Gracilaria edulis extractinduces apoptosis and inhibits tumor in Ehrlich Ascites tumor cells in vivo. BMC Complementary and Alternative Medicine.2013; 13:331. 
Table (1): level of MDA and TAC in mice studied groups.

\begin{tabular}{lccc}
\hline \multicolumn{1}{c}{ Mice Group } & MDA Serum & MDA Liver & TAC \\
\hline -ve control group & $7.25 \pm 1.06$ & $105.03 \pm 1.27$ & $3.20 \pm 0.74$ \\
+ ve control group & $20.21 \pm 4.25$ & $208.684 \pm 4.07$ & $1.46 \pm 0.39$ \\
Therapeutic & $8.60^{* *} \pm 1.56$ & $116.49^{* *} \pm 1.74$ & $2.68^{* * *} \pm 0.37$ \\
group & $57.43 \%$ & $44.17 \%$ & $83.56 \%$ \\
Percent change $\%$ & & & \\
Preventive group & $8.18^{* *} \pm 1.61$ & $108.95^{* *} \pm 1.97$ & $2.91^{* * *} \pm 0.29$ \\
Percent change $\%$ & $59.50 \%$ & $47.79 \%$ & $99.31 \%$ \\
\hline
\end{tabular}

Data were expressed as mean $\pm \mathrm{SD} * * \mathrm{p}<0.001$ was considered highly significant, Percent change $\%$ : values different between positive control group and (Therapeutic, Preventive group).

(A)

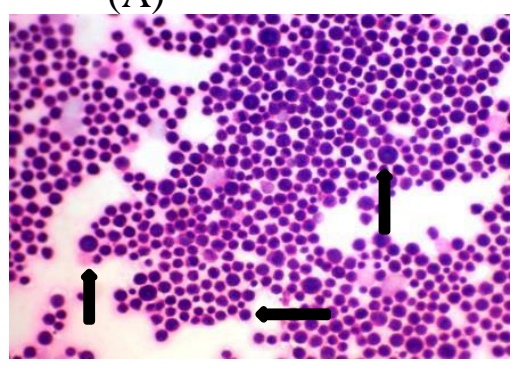

(B)

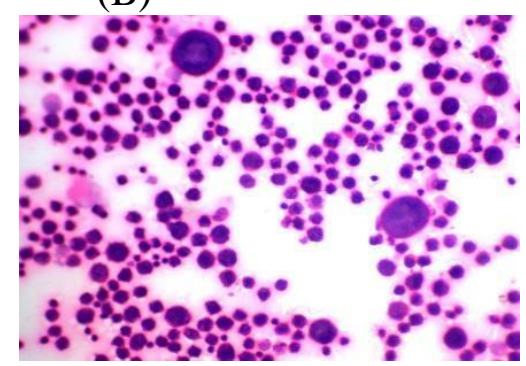

(C)

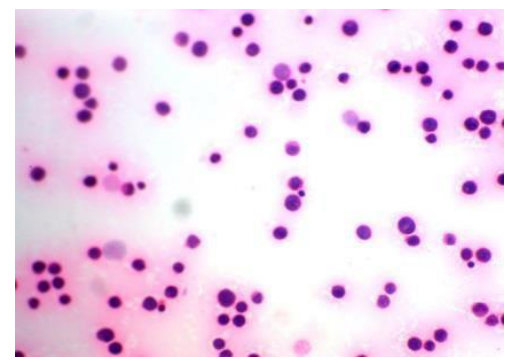

Fig (1): cytological examination of EAC cells. (A) Positive control group. (B) Therapeutic group.

(C) Preventive group(H\&E x400). 
(A)

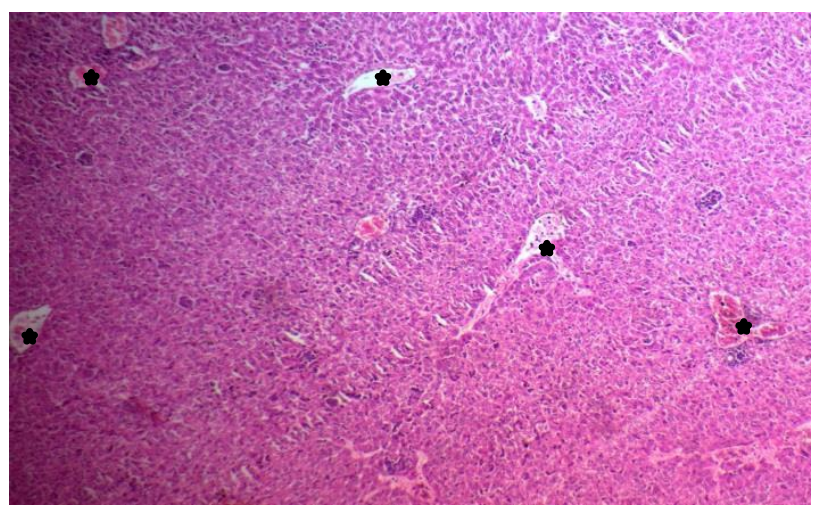

(C)

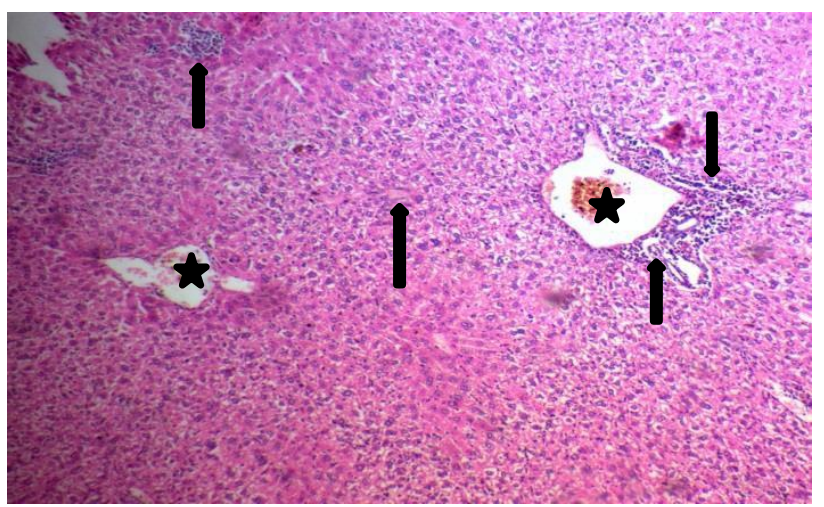

(B)

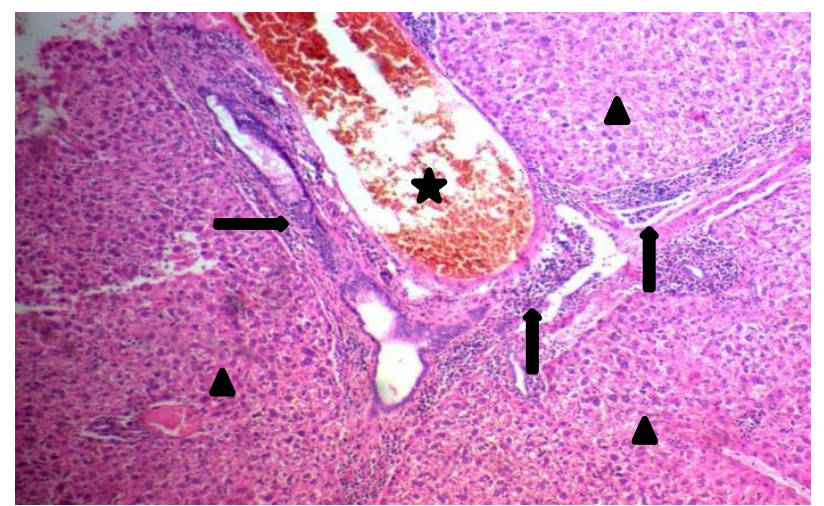

(D)

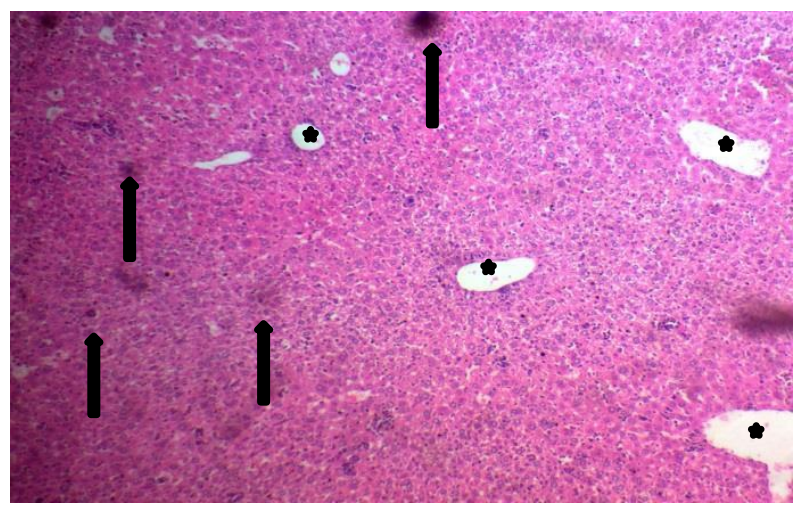

Fig (2): Photomicrograph of liver tissue. (A) Negative control group. (B) Positive control group.

(C) Therapeutic group. (D) Preventive group(H\&E x200). 
(A)

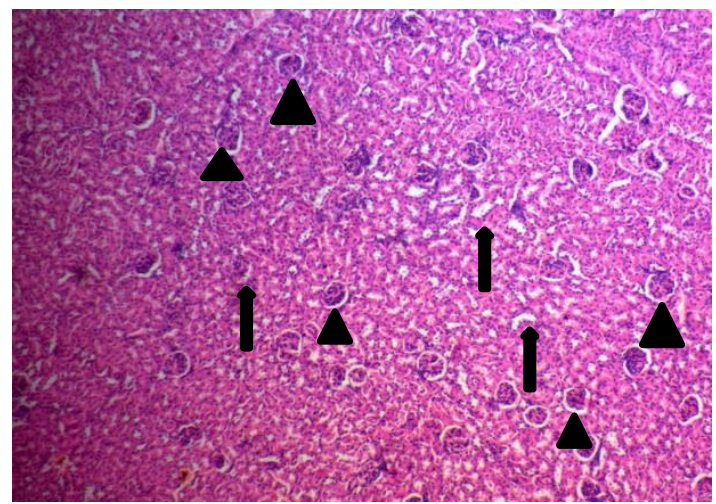

(C)

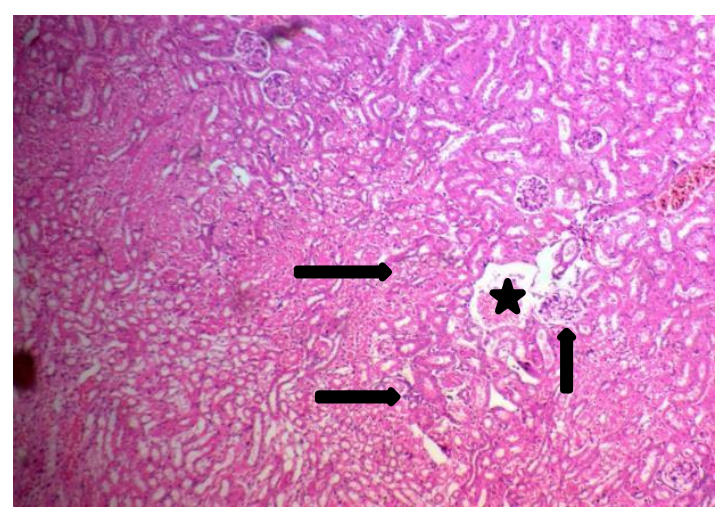

(B)

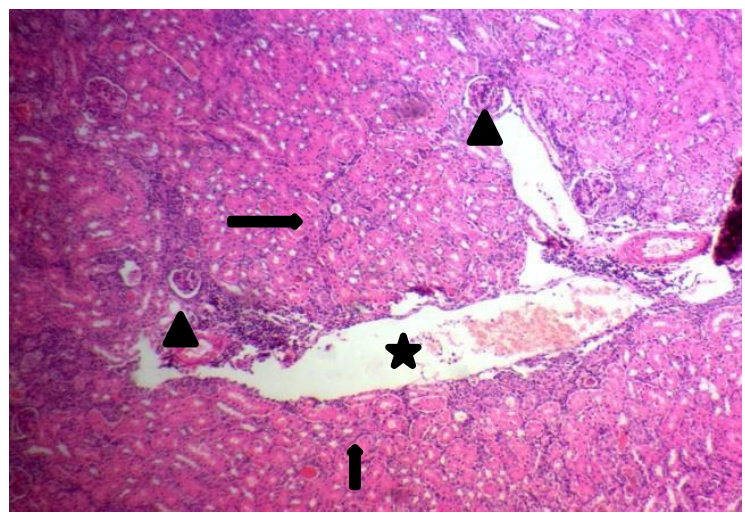

(D)

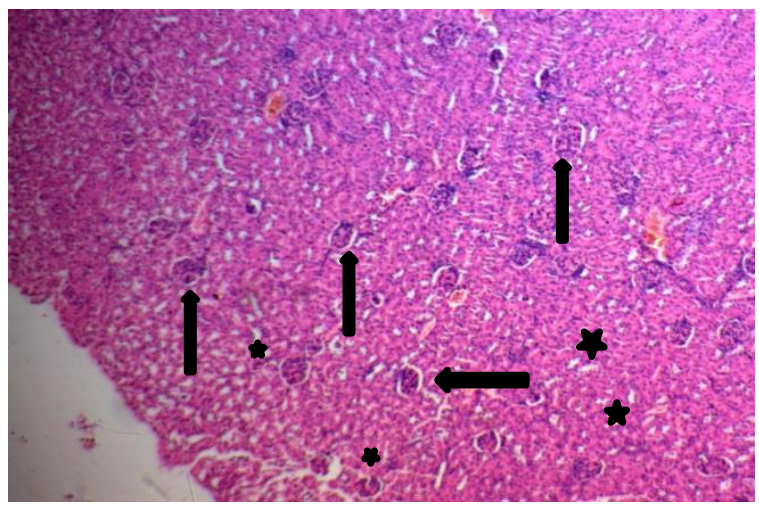

Fig (3): Photomicrograph of kidney tissue (A) Negative control group. (B) Positive control group.

(C) Therapeutic group. (D) Preventive group(H\&E x200). 


\section{Mean Level of TAC on Serum}

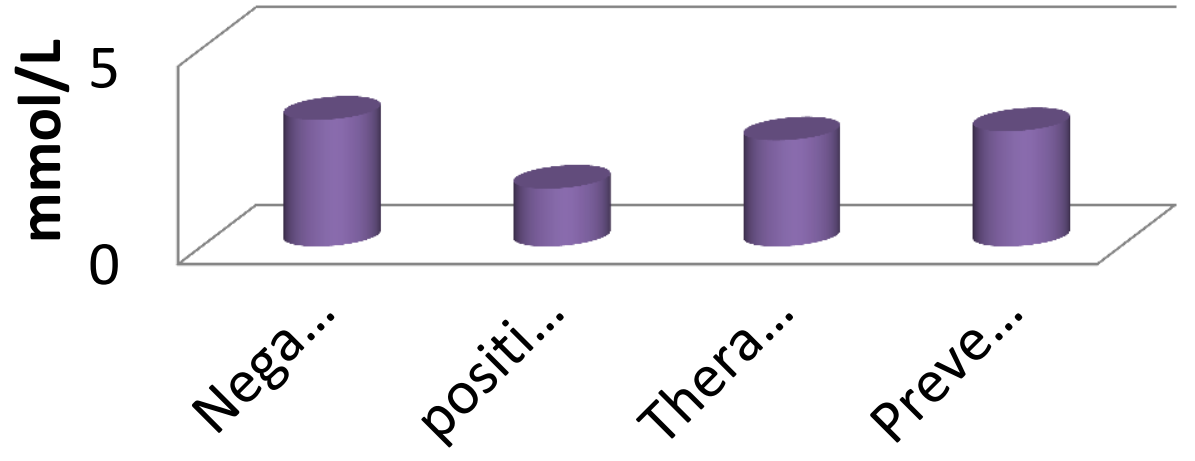

\section{Mean Level of MDA on Serum}

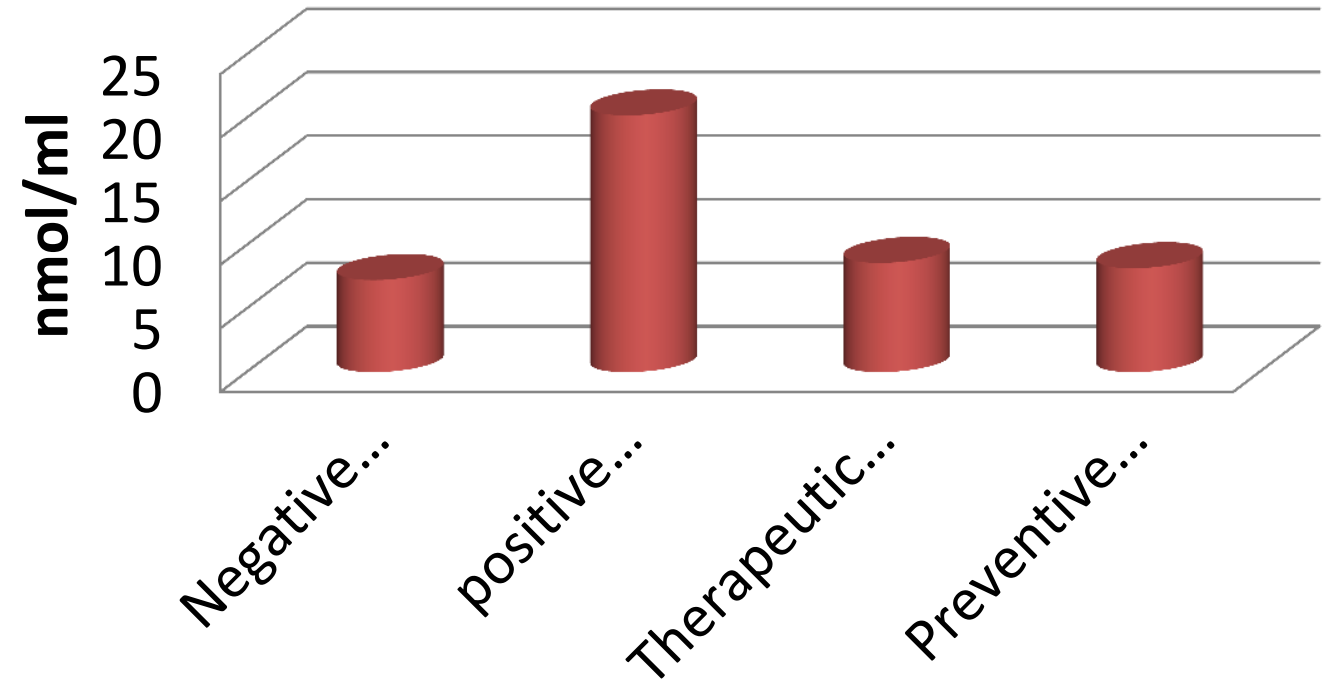




\section{Mean Level of MDA on Liver}

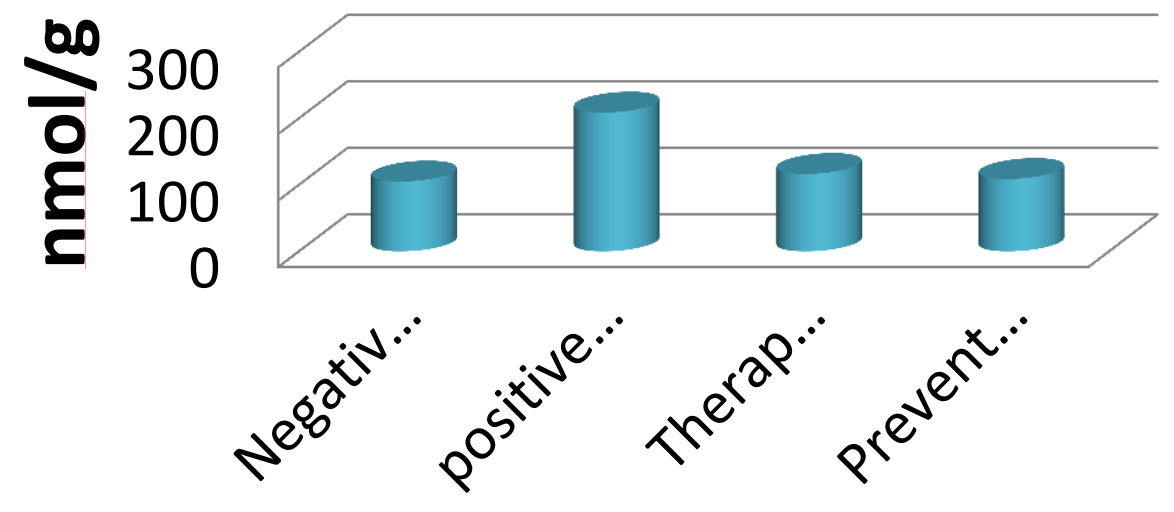

Phytochemical components of the extract.

\begin{tabular}{|c|c|c|c|}
\hline $\begin{array}{l}\text { Phytochemical } \\
\text { components }\end{array}$ & Results & Developed color & Reagent \\
\hline Flavonoids & $+\mathrm{ve}$ & pink color & conc. HCL \\
\hline Alkaloids & $-\mathrm{ve}$ & -ve & Dragendorff's \\
\hline Glycosides & $-v e$ & $-v e$ & Molish's \\
\hline Tannins & $+\mathrm{ve}$ & greenish black color & $\mathrm{Fecl}_{3}$ \\
\hline Triterpenoids & $+\mathrm{ve}$ & reddish brown & $\begin{array}{l}\text { Chloroform, conc } \\
\mathrm{H}_{2} \mathrm{SO}_{4}\end{array}$ \\
\hline Steroid & $+\mathrm{ve}$ & reddish color ring & $\begin{array}{l}\text { (Chloroform+ acetic } \\
\text { anhydride+ conc } \\
\left.\mathrm{H}_{2} \mathrm{SO}_{4}\right)\end{array}$ \\
\hline Anthraquinones & $-\mathrm{ve}$ & -ve & Benzene, $\mathrm{NaOH}$ \\
\hline Saponins & $+\mathrm{ve}$ & Froth & Distilled $\mathrm{H}_{2} \mathrm{O}$ \\
\hline Phenols & $+\mathrm{ve}$ & greenish bluish & $1 \%$ Ferric chloride \\
\hline
\end{tabular}

